\title{
Cotidiano de combate: imagens subvertidas em uma escola pública da cidade de Campinas
}

\author{
Alexsandro Aparecido Sgobin*
}

\author{
Resumo \\ Este texto procura descrever experiências realizadas em uma \\ escola da periferia de Campinas, tendo como inspiração a pe- \\ dagogia libertária, ou anarquista. Com a consciência de que a \\ implantação da própria pedagogia libertária em escolas sob o \\ comando do Estado e, portanto imersas em uma ideologia capi- \\ talista, é praticamente impossível sugerir práticas de aula que \\ busquem "anarquismos": movimentos, pensares, amores, ba- \\ talhas que movimentem o pensamento e abram linhas de fuga, \\ tocando as pretensões libertárias. No caso das experiências \\ descritas neste texto, utilizamos, como possíveis anarquismos, \\ fotografias de pichações que sofreram manipulação digital, \\ tornando-se uma "hiper-realidade". \\ Palavras-chave \\ pedagogia libertária; fotografia; escolas públicas. \\ * Mestre em Educação e \\ membro do Laboratório de \\ Estudos Audiovisuais (Olho) \\ da Faculdade de Educação \\ da Unicamp. Professor \\ de Geografia em escolas \\ estaduais e municipais de \\ Campinas, SP, Brasil. \\ a_sgobin@hotmail.com
}




\title{
Everyday battles: subverted images in a public school from the city of Campinas
}

\begin{abstract}
This paper seeks to describe experiences in a school on the outskirts of Campinas, taking as inspiration the anarchist pedagogy. With the awareness that the implementation of anarchist pedagogy in public schools (immersed in a capitalist ideology) is virtually impossible, we suggest classroom practices that seek for "anarchisms": movements, thoughts, love affairs, battles that move thought and open escape routes, touching the libertarian claims. In the case of the experiments described in this paper we use as possible anarchism photographs of "graffiti", which have undergone digital manipulation, making it a "hyperreality."
\end{abstract}

Key words anarchist pedagogy; photography; public schools. 


\section{Vielas e tags: à guisa de introdução}

A primeira impressão forte para quem chega sem conhecer o lugar é a dos sons: a periferia é eivada de ruído, risos, fala, asfalto que grita, automóveis e gente enchendo as ruas; a música é alta, rap... será o rap o som do gueto?

Enquanto caminho, fotografo o bairro que me acolheu há apenas uma semana; algumas fotos ficarão escuras, porque os becos zombam da iluminação que a manhã traz, escondem-se, ensombrecem; há negócios acontecendo neles que todos aqui conhecem, mas sempre é de mais juízo calar.

Entre as cores da periferia que minha câmera vai captando, qual delas discursa mais forte? 0 verde dos muitos matagais, o cinza das vielas, os tons apagados das casas autoconstruídas, o moreno das peles? Mistura de frio e de fogo sem pretensão estética, as cores deste bairro pobre impressionam e ferem a vista que nelas se demora muito.

Vejo estas cores como gritos imagéticos que se somam ao sonido cotidiano, vozes dissonantes que no dia a dia anunciam, mais que denunciam, a pobreza urbana, corpo cujos órgãos mais-que-vivos são sua gente apressada, a passar rumo ao trabalho, em busca de trabalho, emprego/subemprego, combate - aqui o combate não é figura de retórica. É preciso sobreviver, e a sobrevivência inscreve-se nos rostos marcados que vejo passar, sérios e rápidos; a periferia parece estar sempre apressada.

Passo por vielas que se torcem e torcem o corpo do andante para serem vencidas, descem abruptamente e beijam o chão de terra que orla a parte mais pobre do bairro, com casas pobremente construídas e alguns barracos.

Mães e crianças correm por todos os lados, olhos atentos me acompanham. São os olheiros do tráfico, que dias depois reencontrarei dentro da escola, esta mesma que estou demandando para me apresentar nesta manhã como professor efetivo de Geografia: justo, não estou aqui apenas a tirar fotografias.

Atravesso a chamada “favelinha”, os caminhos são árduos; passar para o outro lado,

- Só pela ponte, irmão.

Onde a pobreza se desnuda? Nos equipamentos urbanos em péssimo estado, nas calçadas rotas, nos muros erguidos com braço rude e ao som do rádio - muros que desdenham do prumo! -, nos ônibus que passam sempre lotados (vazios? Apenas quando se quebram). 0 olhar nunca corre alguns metros, sem se deparar com a trinca, o quebrado, o entulho, o esburacado.

0 mais presente, para mim, entretanto, são as pichações que quase todos os 
muros e fachadas contêm, ininteligíveis, afrontadoras: grafismos selvagens que anunciam esta ou aquela gangue e delimitam seus territórios. Enquanto fotografo as pichações, a rua que subo (feitio de rampa, a inclinação ultrapassa os $30^{\circ}$, seguramente) põe-me à frente dos portões da escola. Será aqui? Nenhuma placa, nenhuma inscrição, apenas a feia arquitetura típica da maioria das escolas públicas me sugere que estou no local certo.

Os muros também estão pichados aqui, caos de caracteres, desenhos, símbolos e tags; e a escola, que toma um grande quarteirão por inteiro, não desfaz da pobreza do bairro que a acolhe, mas a reproduz, representa... e apresenta.

Os portões não convidam a entrar, mudos e austeros: não sei se gosto deles. E, por isso mesmo, entrarei.

\section{Corredores e trancas}

Cheguei muito antes do horário para o primeiro dia de aulas: ninguém à vista no pátio. Ouço o som de uma vassoura e, por absoluta falta de opção (a secretaria está fechada ainda, os portões silenciosos, aluno algum aparece), entro por uma passagem gradeada, passo pelo estacionamento e vou atrás da vassoura e de seu dono, ou dona. É a faxineira: apresento-me, e ela diz que inda falta meia hora para a escola "abrir", donde me sento em um banco de pedra e espero. Mas como ficar parado neste prédio pouco alegre? Resolvo conhecer a escola, enquanto me segue um estranho sentimento de proibido, quase como se eu não devesse estar a andar por corredores que não me convidaram para isso.

A água da torneira tem gosto de ferrugem e algo mais, que é difícil precisar o que seja; andar pelos corredores transmite sensações de frio e desamparo, de vigilância, mas, como não há câmaras nem vigias, descubro, impressionado, que eu mesmo estou a me vigiar (condicionamento? E há quanto tempo fomos condicionados...?)

Impressionante o peso que estes corredores largos, neutros e frios carregam consigo. Os corredores já são todo um discurso: "siga em frente, aqui não se para, tampouco se encosta". "Será assim para os alunos?", penso. O quanto deste peso é apenas reminiscência pessoal e o quanto é real também para os outros?

O silêncio é tão presente que por pouco não escapa aos meus ouvidos o vozerio que se adensa presto do lado de fora dos grandes portões - certamente são os alunos. E aqui estão também já os mestres, que me observam, curiosos, diminuem o tom da voz, saúdam-me com um "bom dia” educado. 
Esta reprodução da pobreza urbana que grassa lá fora!... para onde o olhar se dirige há que achar o trinco, o descascado, o buraco no chão, poças de água e concreto esboroado, tinta apagada e muros que riem do prumo. A música também é a mesma, apenas agora tocada nos celulares dos alunos que entram pelos portões, em grande algazarra.

Vinte minutos depois, entro na sala de aula, é meu primeiro dia enquanto professor efetivo; o barulho é tremendo, um primeiro ano de Ensino Médio. Prenúncio de uma briga nos fundos da classe, gritos, chegam mais alunos, por pouco não me sento às cadeiras pichadas e abro meu caderno, esperando o professor: o sentimento de retroceder ao tempo dos meus quatorze anos é forte o bastante para fazer olvidar, por segundos, que eu sou o professor, e que quarenta e quatro rostos me encaram com leve curiosidade quando repito (pela terceira vez): bom dia.

O contraste entre continuidade e mudança é inegável: os alunos mudaram, sabem mais, têm mais tecnologia à mão, crescem mais rapidamente, seus trajes e dialetos são outros; por outro lado, ouço as mesmas brincadeiras que ouvia quando aluno (já se vão mais de dezoito anos), ainda brincam de forca, grudam os chicletes embaixo da carteira, alguém chora, desencontram-se com o próprio corpo, escrevem nos braços com caneta hidrocor.

O que não mudou?

A sombria arquitetura; ainda os mesmos corredores, a mesma sensação de ser mal recebido pela escola.

0 que não mudou?

A “prova”, que eu mesmo aplicarei no início, sem negar certo prazer em construir as avaliações mais difíceis, convencido de estar a prestar imenso favor à inteligência do aluno.

Não carregava muitos idealismos: menino pobre da cidade, crescendo desgostoso da escola desde os primeiros anos, acostumado às idas à "diretoria” a partir da sétima série, abandonando o Ensino Médio e terminando os estudos em supletivos, havia muito pouco ideal e fantasia a obrar em minha visão da escola. Mas, licenciado em Geografia, por profissão professor, um desejo firmemente construído de ser “diferente" de antigos professores que ocuparam (alguns ainda ocupam) um espaço reservado aos terrores em meus pensamentos vicejava: não devo gritar, como comigo gritaram; não devo humilhar, como já me humilharam; não mandarei ninguém "à diretoria".

Mais poderoso que tal pretensão era o desejo de, inspirado pela chamada pedagogia libertária, introduzir o que chamarei doravante anarquismos: práticas, mo- 
vimentos, amores, conflitos que chamassem o aluno à ação, ao pensamento-ação, desdenhando da rigidez que a escola geralmente aspira a manter. Dentro da sala de aula, do pátio de aula, da rua de aula... turbilhão, e não águas-sempre-plácidas; deixar que se cavassem tocas e se esburacasse o chão, ao invés de desviar-se das tocas já abertas: microguerrilhas?...

\section{Caminhos bifurcados e tags: tentativa de subversões no cotidiano da escola}

A escola pública pode ser vista como um dos instrumentos do Estado, talvez o mais eficiente, na reprodução de valores, ideologias e tradições oriundas de modelos dominantes - no caso hodierno, o modelo capitalista e seus pilares (competitividade, individualismo, meritocracia). Construções do sistema capitalista, como a segregação de classes (social e espacial) e a manutenção de privilégios de grupos favorecidos são reproduzidas no sistema escolar, ao que se acresce a coerção, em forma de visões de mundo que são inculcadas no aluno, muitas vezes, sem que haja grande espaço para a discordância e o diálogo, pois discordar é ser o outro, é suscitar suspeita; há que punir o discordante, para que, ou se encaixe no sistema "correto", construído com grande labor, ou nele seja periferizado.

O Estado estria o espaço; e o que seriam estes estriamentos?

Segundo Deleuze e Guattari (1997), os estriamentos são os espaços sedentários, controlados, normatizados: não convém, aí, que haja o nomadismo, os caminhos múltiplos, a "desordem", contrários aos sistemas de controle do Estado.

Estriamentos seriam, então, os mecanismos, as técnicas, os discursos, as seduções e as violências de captura e controle pelo Estado; espaço geometrizado e normativo: o inusitado é visto com desconfiança. Deixar que se produzissem anarquismos seria, então, alisar os espaços, com toda gama de riscos que isso possa trazer:

0 espaço liso e o espaço estriado, - 0 espaço nômade e o espaço sedentário, - o espaço onde se desenvolve a máquina de guerra e o espaço instituído pelo aparelho de Estado, - não são da mesma natureza [...] devemos lembrar que os dois espaços só existem de fato graças às misturas entre si: o espaço liso não pára de ser traduzido, transvertido num espaço estriado; o espaço estriado é constantemente revertido, devolvido a um espaço liso ( Deleuze; Guattari, 1997, pp. 179-180). 
Contudo, não se tratava de inserir uma experiência de pedagogia libertária na escola em questão ${ }^{1}$, em busca de um alisamento, mas de descobrir, em um caso específico, qual seja, o de uma escola de periferia avaliada pelo próprio Estado como violenta, se práticas inspiradas na pedagogia libertária (anarquismos) poderiam gerar resultados que tocassem, de alguma forma, essa pedagogia e seus reclames (produzissem o chão liso, escorregadio, crianceiro...); este tatear cuidadoso se deve ao fato de que é muito provável que uma experiência de pedagogia libertária em uma escola subvencionada pelo Estado e seu aparato burocrático/normativo tendesse ao fracasso, por não ser aceita por instâncias superiores na própria escola ou por não ser compreendida pelos próprios alunos nela inseridos - talvez seja muito cedo para semelhante experiência, ao menos nas escolas estatais.

Práticas e pensares assim inspirados se sucederam em meio ao diálogo com os alunos de oitavas, sétimas, quintas e sextas séries no ano de 2009: algumas práticas foram descartadas pelos resultados dúbios, outras se tornaram comuns, como aulas fora da sala, abandono gradual da proposta oficial da Secretaria da Educação do Estado de São Paulo em prol da construção, tateante, de um currículo que contemplasse mais fortemente o espaço geográfico mais conhecido peIos alunos: a periferia; a isso se seguiu a eliminação gradual das avaliações com nota, a tentativa de desconstruir a "autoridade autoritária" do professor e enfrentar a construção de uma autoridade cuja natureza foi delineada por Mikhail Bakunin (2000, p.46):

0 princípio da autoridade na educação das crianças constitui o ponto de partida natural: ele é legítimo, necessário, quando é aplicado às crianças na primeira infância, quando sua inteligência ainda não se desenvolveu abertamente. Mas como o desenvolvimento de todas as coisas, e por conseqüência da educação, implica a negação sucessiva do ponto de partida, este princípio deve enfraquecer-se à medida que avançam a educação e a instrução, para dar lugar à liberdade ascendente.

1. Ora, estando inseridos fortemente no sistema capitalista e dele tributários, uma escola, uma classe, um aluno que se fizessem libertários não seriam depois sufocados, como ilhas que submergissem em imenso oceano, pelo status quo vigente? É importante ainda afirmar que cometeríamos uma séria falta, se procurássemos construir uma “pedagogia libertária” em escolas públicas de hoje: falamos da instrução integral, cerne da pedagogia libertária: como promover esta instrução integral da qual fala Bakunin, permitindo aos alunos desenvolver cérebros e mãos, intelecto e corpo? Onde as oficinas? Onde a estrutura? 
Assim o primeiro dia da vida escolar, se a escola recebe a criança em sua tenra idade, quando começa a balbuciar algumas palavras, deve ser o de maior autoridade e de uma ausência quase completa da liberdade; mas seu último dia deve ser o de maior liberdade e o da abolição completa de todo vestígio animal ou divino da autoridade.

Naturalmente, os percalços foram muitos, inclusive com a direção da escola; mas, gradualmente, logrei conseguir a compreensão e o apoio dos alunos sobre o processo em construção, e o passo seguinte foi o estabelecimento de um instrumento (a câmera fotográfica digital) e de potências (fotografias e imagens) como participantes das práticas que estavam sendo gestadas. 0 motivo da escolha foram questões puramente de material: a câmera fotográfica era o instrumento mais disponível para tarefas "extracurriculares", pois a exibição de filmes, por exemplo, exigia planejamentos, agendamentos, transporte de suportes (TVs, cabos...), etc.

Ora, saindo a campo nos arredores da escola, fotografávamos: os objetos para os quais se voltavam o olho e a máquina mudando conforme o assunto em estudo.

Cabe dizer que, no princípio das experiências, a fotografia era utilizada mais como registro dos espaços visitados (fotografia como coadjuvante dos processos: pobreza), obedecendo ao senso comum relativo à fotografia: representação do "real". Mas a leitura de autores que se debruçaram sobre o sentido das fotografias ${ }^{2}$ e a construção de um projeto para a seleção do curso de Mestrado em Educação fizeram com que o uso da fotografia nas aulascomeçasse a extravasaro mero registro etornar-se elemento de apresentação, de criação de mundos, desmonte do preestabelecido... possíveis anarquismos.

O objetivo queria ser a provocação de linhas de fuga no pensamento dos alunos, com o uso de fotografias; rasuras no pensamento, capazes de, quiçá, estimular a dúvida e a criatividade; mas conseguiria provocar estas rasuras? O que os alunos veriam, ou deixariam de ver, nas fotografias que eu thes apresentava? Imagens fotográficas seriam realmente capazes de provocar anarquismos? O que fotografaríamos e por quê?

É experimentar: não há pistas (muito menos respostas!) do que pode acontecer. A primeira sugestão surgiu em aulas cujo tema era mapas temáticos e a sua leitura e construção; o que valia a pena ser cartografado para fins didáticos? Decidi pelas

2. Como, por exemplo, Susan Sontag (1986), Boris Kossoy (2002), Roland Barthes (1984), Pierre e Marie-Claire Bourdieu (2006), José de Souza Martins (2009), entre outros. pichações, que cobrem quase todos os muros e fachadas do bairro em que se situa a escola, decisão baseada na utilização de um elemento bas- 
tante conhecido pelos alunos (o picho), facilmente detectável, e cujo mapeamento era bastante simples - duas gangues de pichadores dominavam aquele bairro e os outros, adjacentes; e suas logomarcas demarcavam com clareza o "território" de cada uma delas (que naturalmente não podia ser "atravessado" pela gangue rival).

Decidimos: vamos fotografar as pichações, para, em seguida, mapeá-las.

Foi assim que, durante três meses, saímos às ruas recolhendo imagens de muros, fachadas e prédios pichados; e, em dado momento, interessando-se pelas nossas fotografias, a direção da escola solicitou uma "campanha anti-pichação", constituída pela exibição das fotografias em telão, no horário do intervalo, seguida de uma palestra sobre a criminalização do picho.

Optei, simplesmente por estética, na ocasião das projeções, por projetar primeiro um conjunto de vinte fotografias sem qualquer transformação das pichações, seguido por vinte fotos com efeitos (aumento de contraste, manipulação de luz e sombra, pequenas colagens); no momento em que se sucediam as imagens sem efeitos, as falas da maioria dos alunos não pichadores revelou a concordância (inconsciente?) com um "estriamento":

- Prá quê é isso aí, mano? Mó feio!

- É do professor Alex isso aí? Não acredito que ele picha!

- Que babaquice...

- Credo... acho isso uma falta de vergonha na cara...

Mas, quando a sucessão de fotografias com efeitos surgia, as reações indicavam alisamentos por parte dos não pichadores...

-É... nossa, que da hora!

- Agora mudou muito...brilho e tal, você viu?

- Ué..

- Mano, olha que da hora!

- Mano, que louco! Ficou da hora!

- Porra!...foi o cara [professor] que fez?!

Uma potência se desenhava naquele pátio... possibilidade de anarquismos através das fotografias de picho com efeitos? 
A pichação, movimento odiado por muitos, o que se tornaria na fotografia com efeitos (o que supõe uma "vontade de arte" do professor)? contravenção-arte?, crimepoesia?, crimesó?, crimearte? poesia de rua?...

Que haveríamos, ao final? Que possibilidades de mirada se abririam, acentuando contrastes, luzes, sombras, em busca da hiper-realidade? Resolvo imprimir algumas fotografias e apresentá-las aos alunos em diversos momentos.

Vejamos o picho a seguir, fotografado em uma avenida próxima à escola:

\section{Fotografia $n^{\circ} 1$}

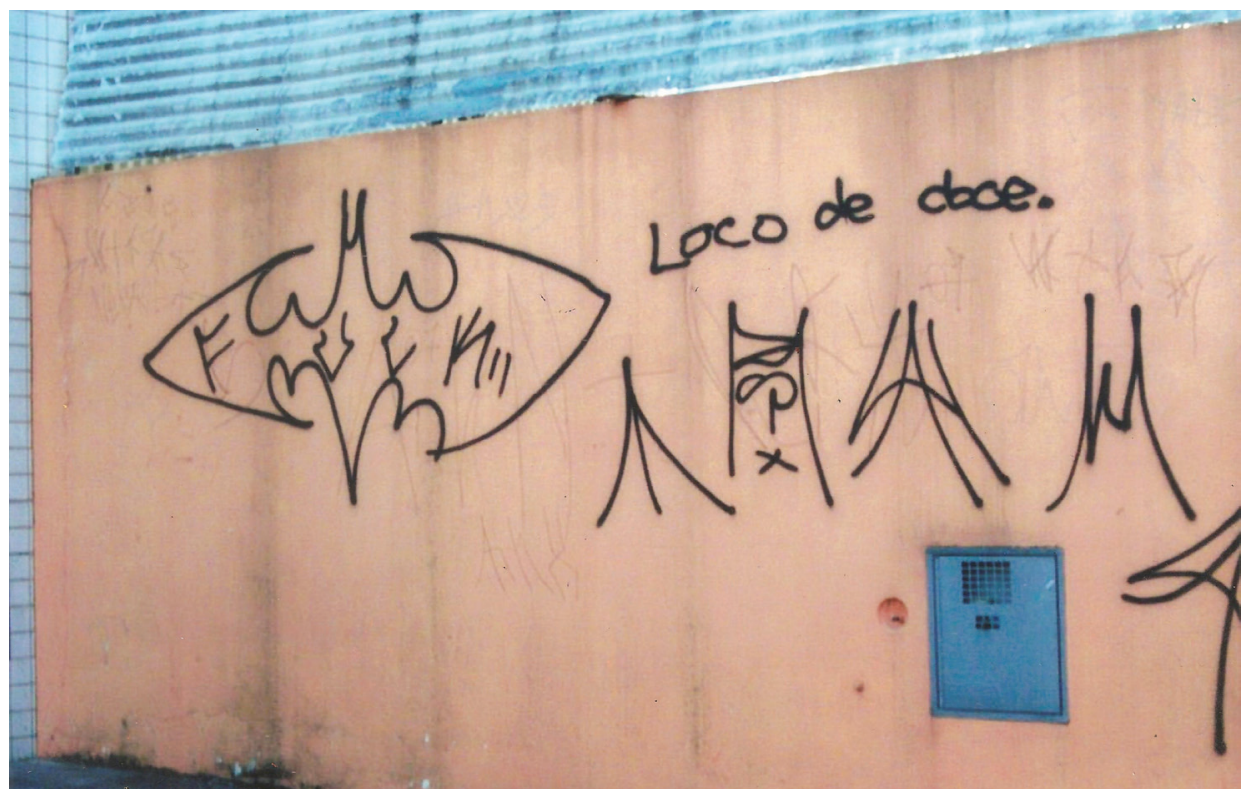

Esta fotografia, impressa e passada de mão em mão, provoca reações díspares: muitos alunos acham "feio", "crime”, "mau-gosto”; outros estão em dúvida, enquanto os pichadores consideram este picho histórico:

- Valeu professor, eternizou o rolê do nosso mano!

E, então, inseri efeitos na mesma fotografia: 


\section{Fotografia $n^{\circ} 2$}

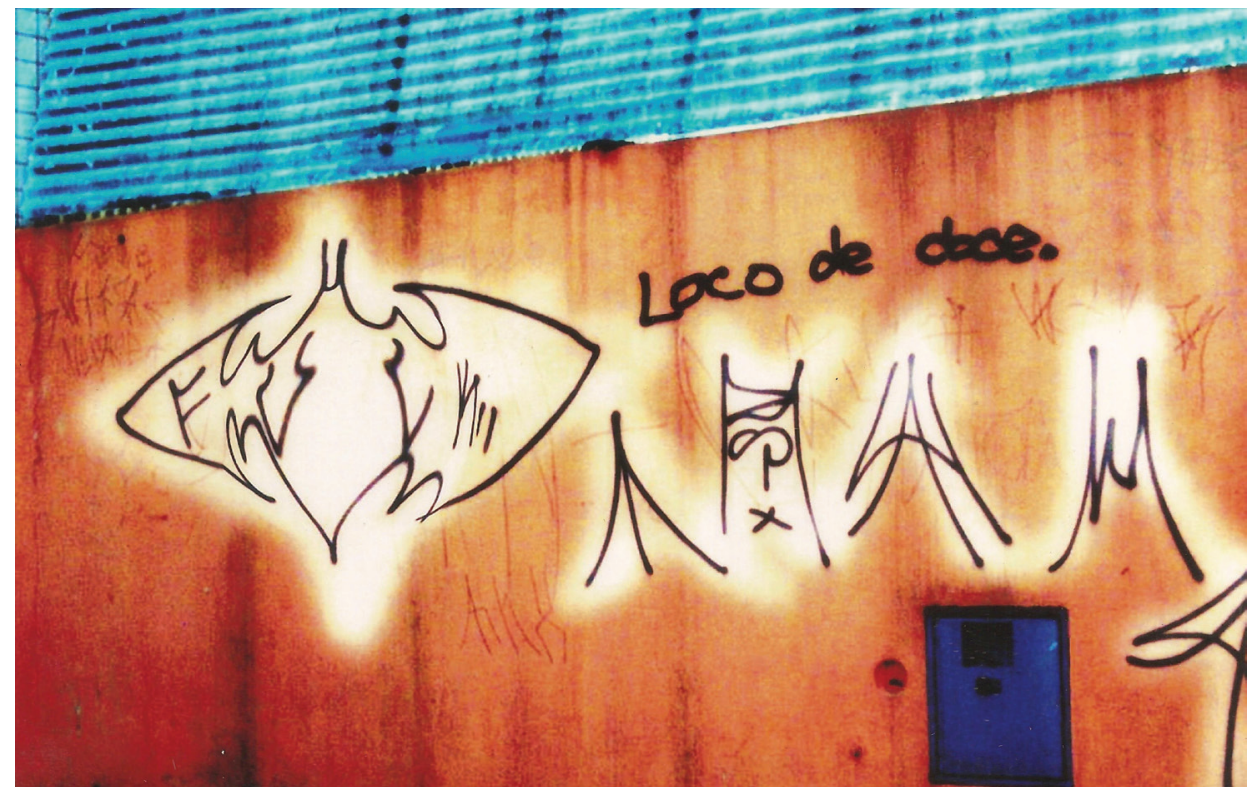

As falas mudam...

-É a mesma foto, professor? Que da hora...ficou bonito...

- Mas antes era feio?

- Era, né? Pichação é vandalismo...

- Mas é o mesmo muro e a mesma pichação...

- Mas não é a mesma fotografia!

- Esta foto [sem pós-produção] é crime?

$-\hat{E}$.

- E esta [mostro a foto pós-produzida da mesma pichação], mostra um crime também?

- Ahn...sim...ou não?! Não sei!...

Eles duvidam, o pensamento se tensiona, dá voltas, avança, baila: anarquismos se mostram possíveis. Esta foto é uma outra imagem, um outro mundo, um múltiplo mundo, que quer ser ainda mais provocante, não registro, apresentação... quer dançar com o pensamento, ser crimideia, ter ainda mais potência que uma fotografia comum. 
Susan Sontag (1986) diz:

Toda foto tem múltiplos significados; de fato, ver algo na forma de uma foto é enfrentar um objeto potencial de fascínio. A sabedoria suprema da imagem fotográfica é dizer: "Aí está a superfície. Agora, imagina ou, antes, sinta, intua - o que está além, o que deve ser a realidade, se ela tem este aspecto".

Ir além da natureza já em si potente da fotografia, como quer Susan Sontag? Talvez seja possível: percebo, no olhar e no estranhamento dos alunos aos quais apresento as fotografias de pichações com efeitos, este ir além, uma potência de linha de fuga, uma possibilidade de anarquismos no/do pensamento, através das imagens, reverberações não previstas, caminhos e atalhos inusitados...

Se, manipulando imagens, eu as procuro tornar novas, movimento-as, anarquizando suas linhas e supostas verdades, não permito ao olhar que as contempla momentos de, também, anarquias do ver e sentir?

Criação de mundos, mundos-imagem, de multiplicidades e diálogos, espantos, abrindo perguntas e desvios: isto que vejo na fotografia é um fragmento da periferia que lá fora viceja, pedaço de periferia que é geralmente odiado: as pichações, o grafismo selvagem das pichações. Mas houve alisamentos nesse ódio: os efeitos nas fotografias fizeram o olhar de vários alunos vagabundearem indecisos entre o crime e a arte, e é então que o pensamento entra em movimento (ainda não há captura).

Quando subverto e apresento tais fotografias, instigo o estranhamento, e a busca é a do pensamento anárquico, desirmanado de lugares-comuns e impressões "aceitas" sobre a pichação, a periferia, o que é marginal, o que se considera real. Misturar e dançar com o imaginário e o "real”: permitir descobertas, ou melhor, convidá-las, sem saber se virão. E quem poderia prevê-lo? E para que querer prevê-lo?

A decisão de emprestar às fotografias de pichação níveis os mais altos possíveis de contraste e saturação, com leves modificações de formas; de fazer tais fotografias bailarem com outras imagens colocou em suspenso, para vários alunos, o caráter documental da fotografia e da imagem comumente usada em práticas de aula; mas houve capturas também, pensamentos que param... 


\section{Fotografia no 3}

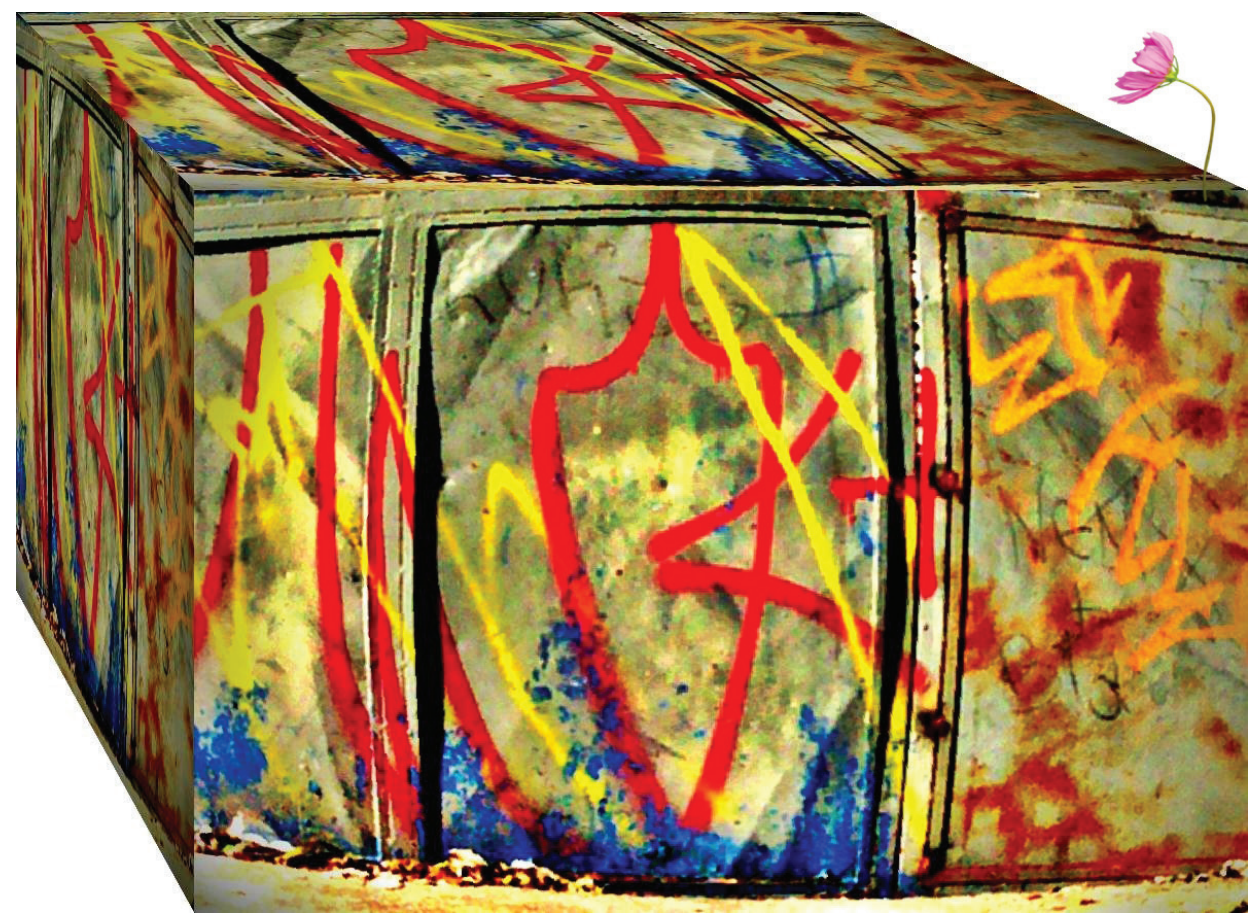

Se:

"Isso aí é uma arte".

"Ah, isso é arte. Com certeza, arte".

"É arte".

"Poxa, eu acho bem mais legal as cores, não parece vandalismo, é bem mais interessante, assim, de ver".

"Diferente da outra. É um modo de expressar alguma coisa, está mais perto de arte, mesmo que seja a mesma foto, viu?".

Notem-se as "capturas" (o pensamento parou e decidiu) nas falas de alguns alunos: capturas surgiram, na maioria das vezes, quando a "vontade de arte" do professor foi imediatamente identificada pelos alunos. A decisão de fazer algumas imagens fugirem bastante do "real” ("real”: pichação), procurando fazer deslizar radicalmente seu suposto caráter indicial, parou os pensamentos: “isto é arte”. Dever-se-ia, então, procurar um "caminho do meio"? 
Demasiado simplista esta proposição: melhor aceitar que os anarquismos não nos darão certeza alguma de que surtirão efeitos, se beijarão os alunos ou será por eles beijado... imprevisível, nunca saberemos onde surgirá um nova onda nas águas, por quais caminhos um vagabundo seguirá, e o marulhar e o vagabundo foram convidados a adentrar a sala de aula e provocar os alunos; talvez entrem, ou talvez apenas espiem.

Talvez sejam postos para fora [estriados].

Ora, creio haver mostrado que pensamentos nômades, vagabundos, ocorreram entre os alunos quando da mirada/namoro com algumas fotografias com efeitos dos pichos; por que não ocorreriam com imagens do mundo, das gentes, das coisas, alteradas de forma a desviar-se do caráter indicial e permitir bailados mais intensos, desarrumados, alegres, tensos, anarquistas? Desarrumar as imagens usadas em sala de aula: não haveria aí potências, fotopotências que talvez gerem anarquismos?

Se desarrumássemos imagens nos livros didáticos? Se gatos caminhassem em meio às águas dos rios na imagem? Se pichássemos as montanhas e o Sol?

E se...? E se...? E se...?

\section{Referências bibliográficas}

BAKUNIN, M. A. Deus e o Estado. São Paulo: Imaginário, 2000. 95 p.

BARTHES, R. A câmara clara: nota sobre a fotografia. Rio de Janeiro: Nova Fronteira, 1984. $141 \mathrm{p}$.

BOURDIEU, P.; BOURDIEU, M.-C. O camponês e a fotografia. Revista de Sociologia e Política, Curitiba, n. 26, p. 31-39, jun. 2006. Disponível em: http://www.scielo.br/pdf/ rsocp/n26/ao4n26.pdf. Acesso em: 08 fev. 2011.

DELEUZE, G.; GUATTARI, F. Mil platôs. São Paulo: Editora 34, 1997. v. 5.

KOSSOY, B. Realidade e ficções na trama fotográfica. São Paulo: Ateliê Editorial, 2002. $149 \mathrm{p}$.

MARTINS, J.S. Sociologia da fotografia e da imagem. São Paulo: Contexto, 2009. 206 p. SONTAG, S. Ensaios sobre a fotografia. Lisboa, Portugal: Dom Quixote, 1986. 178 p.

Recebido em o8 de junho de 2011 e aprovado em 14 de novembro de 2012. 